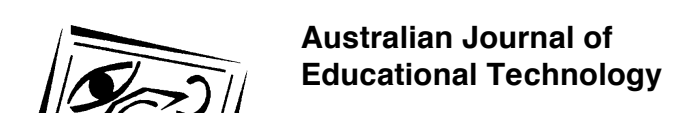

2001, 17(3), 313-329

\title{
Longitudinal study of computer usage in flexible engineering education
}

\author{
Stuart R. Palmer and Sharyn L. Bray \\ Deakin University
}

\begin{abstract}
A longitudinal analysis of computer usage by commencing students in Deakin University's undergraduate engineering and technology programs over the period 1998 to 2001 revealed that; access to computers was at high levels; mean computer usage for off campus students had not changed significantly, but had risen significantly for on campus students; while access to the Internet / WWW had not increased significantly, reported regular use of the Internet / WWW had risen significantly; while most students continued to report their source of Internet / WWW access as either home or university, the proportion reporting home as their source of access had risen significantly; and the reported regular use of email rose significantly. Other results are also presented.

These results imply that commencing engineering and technology students are well placed to adopt online delivery and support of teaching and learning. However, while it might now be reasonable to assume that all students have access to computers and the Internet, the experiences of on campus students in computer laboratories with broadband network access will be different from off campus students accessing the Internet via a dialup modem connection. A small proportion of commencing students where unaware of the computing facilities provided by the university; an orientation program covering computing facilities and services would benefit all commencing students.
\end{abstract}

\section{Introduction}

Computers and information technology play an important role in the delivery of flexible engineering education programs at the School of Engineering and Technology, Deakin University. To assist in understanding the computer usage patterns of students at the commencement of their undergraduate engineering studies, surveys had been conducted over a number of years. Based on anecdotal observations and apparent trends, it was hypothesised that for Deakin engineering and technology students: 
- student access to computers was rising and approaching 100 percent;

- student computer usage was rising,

- computer usage for off campus students would be higher than on campus students;

- student access to the Internet was rising;

- student usage of the Internet was rising;

- the proportion of students with access to the Internet at home was rising; and

- student usage of email was rising.

Developments in computing technology are rapid, and effective planning and development of policy and resources for computers in education requires an understanding of trends in student computer use. To test these hypotheses, a detailed longitudinal analysis of the survey data was undertaken. This paper presents the analysis and a discussion of the findings.

\section{Computers in engineering and technology education}

Just as computer and communication technologies pervade many aspects of our lives, computers have many roles to play in education. These roles include not only classroom teaching and learning experiences, but also administration, teacher training, the planning and development of educational material and general communications. When the 'power' of global networked communications is added to computer applications we have the Internet. The Internet offers a new range of educational technologies to educators that includes: electronic mail, file transfers, the multimedia capability of the World Wide Web (WWW), low cost, desktop videoconferencing, online, interactive tutorials, real time group conferencing, remote access to laboratory experiments and 3D interactive modelling.

For engineering and technology education, computer applications can include computer programming, numerical analysis, computer simulation, Computer Aided Design (CAD), Computer Aided Manufacture (CAM), electronic communications, information retrieval and computer aided learning and assessment. The use of computers in education is particularly relevant to engineering education, as the computer has become one of the central tools of the practicing engineer, whether it be for CAD, project planning, process control, budgeting, data communications or software development.

The Deakin University engineering and technology programs are offered in flexible delivery mode, and a key emerging issue in flexible delivery of education programs is the development and delivery of online study programs. Ryan (1998) notes that 'flexible delivery' and 'Web based 
delivery' have become synonyms, as well as the 'inevitability' of online delivery in education - "Time and tide are inexorable forces. Teaching and learning online is equally unstoppable..." (Ryan, 1998, 14).

Ubell (2000) notes a US government report estimating that by 200215 percent of American higher education is likely to be delivered online, and that in 199940 percent of the money spent on corporate training in America was for online education. The same source identifies engineers as key consumers of online education, based on the short half life of technical knowledge and the need for the engineering workforce to continually refresh their knowledge and skills base:

E-learning, especially for engineers and executives in technology industries, has emerged as one of the fastest moving trends in higher education...As any engineer knows, there is tremendous pressure to keep pace with the latest technology and the newest ways of doing business... Yet few engineers have the luxury of attending classes on well groomed college campuses (Ubell, 2000, 60)

\section{Engineering and technology programs at Deakin University}

The School of Engineering and Technology at Deakin University offers a three year Bachelor of Technology and a four year Bachelor of Engineering at the undergraduate level, and Masters and Doctoral engineering programs at the postgraduate level. All of these programs are available via flexible delivery mode. The programs are based on a model of flexible delivery systems (Briggs, 1995) that incorporates:

- a modular curriculum;

- a formal assessment system for recognition of prior learning (both academic and experiential) based on granting advanced standing in appropriate course modules;

- course modules developed in print form, supplemented by an array learning resources, including audio and video presentations, home experimental kits, computer aided learning packages, remote (Internet based) laboratory experiments and conventional laboratory work requirements; and

- computer mediated communication systems, including email, video conferencing, WWW based bulletin boards and Internet based conferencing.

A number of course modules go together to form a unit (subject). A full time student would normally study four units per semester, and eight units per year. A three-year Bachelor of Technology is comprised of 24 units; a four-year Bachelor of Engineering is comprised of 32 units. The undergraduate programs are delivered on campus, full time for conventional entry students who come directly from secondary school. 
Mature age students may study the programs off campus and/or part time. The use of computers is an integral part of all the engineering study programs.

The university centrally supports and provides (on a CD-ROM) at no cost to students, application software for email, computer conferencing, virus protection, bibliographic database management and access to online research databases. On campus students have access to computer labs where all required software has been installed. Where a software package is to be used in a study unit, a key selection criterion is the availability of a low cost, student edition of the package, so that purchase of the package can be made compulsory for off campus students. This may involve negotiation with software suppliers for special student pricing, or for the 'leasing' of software that off campus students must return at the end of the semester.

The aim is that off campus students are not required to attend the campus to complete their studies that require the use of computer applications. Computer programming exercises are coded, compiled, run and debugged remotely by off campus students. Program listings and evidence of program performance would typically be submitted for assessment. Similar requirements exist for numerical analysis and computer simulation exercises. CAD exercises require students to draft their drawings on their computer remotely and submit their drawing files on floppy disk. CAM exercises require students to develop and validate their machine control programs remotely and submit them on floppy disk so that actual parts can be machined in a flexible manufacturing cell. A recent development at Deakin University allows students to submit their CAM files via the Internet directly to a computer that controls the flexible manufacturing cell, and then watch live video, via the Internet, of their part being machined (Ferguson \& Florance, 1999). The School of Engineering and Technology has also developed a number of special purpose Computer Aided Learning (CAL) packages covering areas as diverse as taking measurements with a micrometer to understanding moral decision making (Palmer \& Tulloch, 2001).

Over a number of years one of the authors has conducted surveys of commencing engineering and technology students to assess their level of access to computers and their usage of computers. A philosophy of flexible delivery of engineering education supported by computer based learning materials and/or online delivery will only be effective if students have access to the required computer systems and the ability to use such systems effectively. While it might be considered as an accepted fact that levels of computer access and usage would be high among commencing science and engineering students, a previous study of commencing 
chemistry students at Deakin University showed that while the rate of access to computers was high, this did not necessarily translate into uniformly high levels of computer usage or IT competence (Lim \& Lee, 2000). The increasing but non-uniform access to, and use of, computers is documented elsewhere (Flowers, Pascarella, \& Pierson, 2000). To gain an appreciation of the changes in computer usage over time of the commencing engineering and technology students at Deakin University, a longitudinal comparison of the collected data was undertaken to test the stated hypotheses.

\section{Methodology}

Computer usage surveys were conducted in 1998, 1999 and 2001. While the questionnaire format used varied slightly over the period in question, much of the data collected is directly comparable. The first questionnaire used is presented in the Appendix and is typical of the form and content employed in all three questionnaires. The questionnaires were of a simple form; multiple item scales were not employed and a reliability index was not computed. The sample student population was the enrolment in the level one unit SEB121 - Fundamentals of Technology Management. SEB121 is common to all study programs in the School of Engineering and Technology, and is taken by most on and off campus students in the first semester of the first year of their undergraduate studies. A questionnaire delivered to this student group should provide a comprehensive snapshot of the computer usage patterns of engineering and technology students at the commencement of their studies. The questionnaire was administered at the commencement of the first study semester in years noted above. Time in the very first class was set aside for on campus students, and the questionnaire was mailed with a reply paid envelope to all off campus students at the commencement of the semester. As required by Deakin University research ethics procedures, participation in the survey was anonymous and voluntary.

In addition to these surveys, the same questionnaire used for the commencing class in 1998 was also administered to the level four unit SEB421 - Strategic Issues in Engineering, in 1998. SEB421 is normally taken in the final semester of final year, and while the results obtained are not directly comparable to those from the commencing groups, they do provide a comparison of the difference in responses between students just commencing their studies and those just prior to the completion of their studies.

Survey questions that were common to all questionnaires included the following areas: 
- demographic information - age and gender;

- access to computers - yes / no;

- computer usage - average hours per week usage;

- Internet / WWW access - yes/no;

- source of Internet / WWW access - home/university / other;

- Internet / WWW usage - regular user or not; and

- email usage - regular user or not.

Demographic information was analysed to confirm that the characteristics of the three commencing student groups were not significantly different and that valid comparisons could be made. The remaining information from the common questions relating to computer access and usage was analysed to identify significant trends over time. The particular statistical methodologies employed depend on the characteristics of the data. An explanation of each statistical methodology is given with the results below. For this research project a significance level (p) of 0.05 was used.

\section{Results and discussion}

\section{Response rates}

Table 1 gives the unit enrolment, number of valid questionnaire returns received and the corresponding response rates for the four surveys included in this study.

Table 1: Questionnaire response rates

\begin{tabular}{|l|c|c|c|c|}
\hline Unit & Year & Enrolment & Returns & Response rate \\
\hline SEB121 & 1998 & 141 & 76 & $53.9 \%$ \\
\hline SEB121 & 1999 & 179 & 122 & $68.2 \%$ \\
\hline SEB121 & 2001 & 178 & 101 & $56.7 \%$ \\
\hline SEB421 & 1998 & 42 & 26 & $61.9 \%$ \\
\hline
\end{tabular}

\section{Demographic information}

Table 2 gives the mean respondent age and the associated standard deviation for the SEB121 groups; the mean age of the SEB421 group is not directly comparable. The distributions of respondent age all had a large peak at 18 years (representing conventional entry students commencing directly from secondary school) and a large flat tail (representing mature age students with a wide variation in age). This distribution was not Gaussian, however the distributions of three groups were very similar, permitting a Kruskal-Wallis test of population medians. Under this test the mean respondent age was not significantly different between the three groups $(\mathrm{H}=3.12, \mathrm{p}>0.21)$, though had decreased slightly over the period 
under study; perhaps reflecting the anecdotal observation of the authors that an increasing proportion of mature age students are being exempted from SEB121 on the basis of prior learning and/or workplace experience.

Table 2: Mean respondent age and associated standard deviation

\begin{tabular}{|c|c|c|}
\hline Year & Mean respondent age & Standard deviation \\
\hline 1998 & 22.2 years & 7.47 \\
\hline 1999 & 21.1 years & 6.82 \\
\hline 2001 & 20.0 years & 4.81 \\
\hline
\end{tabular}

Table 3 gives the gender proportions for the SEB121 groups. The three sample groups were large and random, so the Chi-square test of homogeneity was applicable. The gender proportions were not significantly different between the three groups $\left(\chi_{2}^{2}=3.14, p>0.2\right)$. These gender proportions compare to the reported overall commencing female participation rate in Australian engineering undergraduate studies of approximately 14.4 percent (Department of Education Training and Youth Affairs, 1999).

Table 3: Gender proportions of respondent groups

\begin{tabular}{|c|c|c|}
\hline Year & $\begin{array}{c}\text { Proportion of female } \\
\text { respondents }\end{array}$ & $\begin{array}{c}\text { Proportion of male } \\
\text { respondents }\end{array}$ \\
\hline 1998 & $22.4 \%$ & $77.6 \%$ \\
\hline 1999 & $13.1 \%$ & $86.9 \%$ \\
\hline 2001 & $14.9 \%$ & $85.1 \%$ \\
\hline
\end{tabular}

These results indicate that valid comparisons can be made between the three groups of commencing students.

\section{Computer access}

Table 4 gives the proportion of respondents in the SEB121 groups who indicated that they had access to a computer. The results suggest that computer access has increased over time. However, all of the proportions were relatively high and, based on the Chi-square test of homogeneity, comparing all three groups indicates that the difference between them was not significant $\left(\chi_{2}^{2}=5.53, \mathrm{p}>0.06\right)$. As the samples were large and random, the large sample inference about two proportions test could be applied to pairs of year groups. A significant difference was found between the 1998 and 2001 results $(Z=2.00, p<0.046)$, lending some weight to the proposition that more recent commencing students are more likely to have access to a computer, and that the proportion of students with access to a computer has reached 100 percent. 
Table 4: Proportions of respondents who had access to a computer

\begin{tabular}{|c|c|c|}
\hline Year & $\begin{array}{c}\text { Have access to a } \\
\text { computer }\end{array}$ & $\begin{array}{c}\text { Do not have access to a } \\
\text { computer }\end{array}$ \\
\hline 1998 & $96.0 \%$ & $4.0 \%$ \\
\hline 1999 & $99.2 \%$ & $0.8 \%$ \\
\hline 2001 & $100.0 \%$ & $0.0 \%$ \\
\hline
\end{tabular}

These results are broadly in agreement with computer access rates of 91 to 100 percent reported by students in an Australian, on campus, undergraduate applied science course (Ash, 1996), and 98 percent from a recent survey of first year chemistry students (also at Deakin University) ( $\operatorname{cim} \&$ Lee, 2000). While it is recommended to students entering the undergraduate engineering programs at Deakin University that they have access to a computer, it has not been made a mandatory requirement for entry on the basis of equity and access; principally due to concerns that off campus students may not necessarily have access to and/or be able to afford a computer. The results here suggest that for the students who elect to undertake engineering studies, access to computers is not a significant issue.

\section{Computer use}

Table 5 gives the mean reported hours per week computer usage and associated standard deviation for the SEB121 groups. The data is further broken down into student study modes - on and off campus combined (all students), on campus only and off campus only. The three study mode distributions were not Gaussian, however the distributions of the three groups were very similar, permitting a Kruskal-Wallis test of population medians. When both on and off campus students were considered together, there was a significant difference between the groups' reported computer usage $(\mathrm{H}=14.00, \mathrm{p}<0.001)$, but no trend was apparent.

Table 5: Reported mean (and standard deviation) hours per week computer usage

\begin{tabular}{|c|c|c|c|}
\hline Year & On and off campus & On campus only & Off campus only \\
\hline 1998 & $10.6(13.36)$ hours & $6.0(7.90)$ hours & $23.3(16.89)$ hours \\
\hline 1999 & $9.1(9.56)$ hours & $7.0(5.69)$ hours & $19.8(16.20)$ hours \\
\hline 2001 & $13.1(12.49)$ hours & $11.7(11.21)$ hours & $24.8(16.60)$ hours \\
\hline
\end{tabular}

However, a closer examination revealed there was a marked difference between the reported computer usage of on and off campus students; on campus usage appeared to be rising, while off campus usage did not. Considering the three groups of off campus student data, there was no 
significant difference in computer usage $(\mathrm{H}=0.85, \mathrm{p}>0.65)$. Considering the three groups of on campus student data, there was a significant difference in computer usage $\left(\mathrm{H}=27.83, \mathrm{p}<9.1 \times 10^{-7}\right)$.

On campus students in the Deakin University engineering programs are principally those entering directly from secondary school with a nominal age of 18 years at the commencement of their studies (these 'conventional entry' students are not normally permitted to study in the off campus mode until they reach 20 years of age). Off campus students are principally mature age (defined as 20 years or older at the commencement of their studies), with a wide variation in age, previous studies and personal circumstances. It is their personal circumstances that lead to mature age students normally studying in the off campus mode; many of these students live remotely from the university and/or have full time employment and/or are returning to study to upgrade their qualifications to improve their career prospects and/or are participating in employer sponsored study programs. It is theorised that the much higher mean reported computer usage for mature age students is related to their employment status and occupational use of computers.

It is interesting to note that while the reported off campus computer usage has not varied significantly during the study period, the reported on campus computer usage has varied significantly, almost doubling during the study period. This suggests that the exposure to and use of computers by leaving secondary school students is increasing rapidly.

\section{Internet access / use}

Table 6: Reported access and regular usage of Internet / WWW

\begin{tabular}{|c|c|c|}
\hline Year & Internet / WWW access & Regular Internet / WWW user \\
\hline 1998 & $84.2 \%$ & $46.1 \%$ \\
\hline 1999 & $90.2 \%$ & $52.1 \%$ \\
\hline 2001 & $92.1 \%$ & $82.0 \%$ \\
\hline
\end{tabular}

Table 6 gives the proportions of respondents in the SEB121 groups who indicated that they had access to the Internet / WWW and who indicated that they were 'regular' users of the Internet / WWW. There appeared to be increasing access to the Internet / WWW over time, however, all the access proportions were relatively high and, based on the large sample inference about two proportions test, even the difference between the 1998 and 2001 results were not significant $(Z=-1.64, p>0.1)$. While the self assessment by respondents as to what constitutes regular Internet / WWW usage may be somewhat subjective, the results showed a marked 
increase in regular usage over time, and, based on the Chi-square test of homogeneity, this increase was significant $\left(\chi_{2}^{2}=29.54, p<3.9 \times 10^{-7}\right)$. These results are broadly in agreement with 86.6 percent of Deakin University first year chemistry students reporting themselves as knowing how to use the WWW (Lim \& Lee, 2000).

Those respondents that indicated they had Internet / WWW access were asked to indicate the source of that access by selecting from Home, University or 'Other'. Figure 1 gives the proportion of respondents indicating each of these sources of access for the SEB121 groups. The majority of students indicated their source of access as either Home or University. Over the period of the study the proportion of respondents indicating their source of access as 'Other' remained small. The remaining 95-97 percent of respondents indicated either Home or University as their source of Internet / WWW access, and, based on the Chi-square test of homogeneity, the relative proportions of these two sources did change significantly over the period of the study $\left(\chi_{4}^{2}=11.54, p<0.022\right)$. From 1998 to 2001 there was a greater than 60 percent increase in the proportion of students indicating that Home was the source of their Internet / WWW access at the commencement of their studies. This increase mirrors the more than 70 percent increase over the same period in respondents reporting themselves as regular Internet / WWW users.

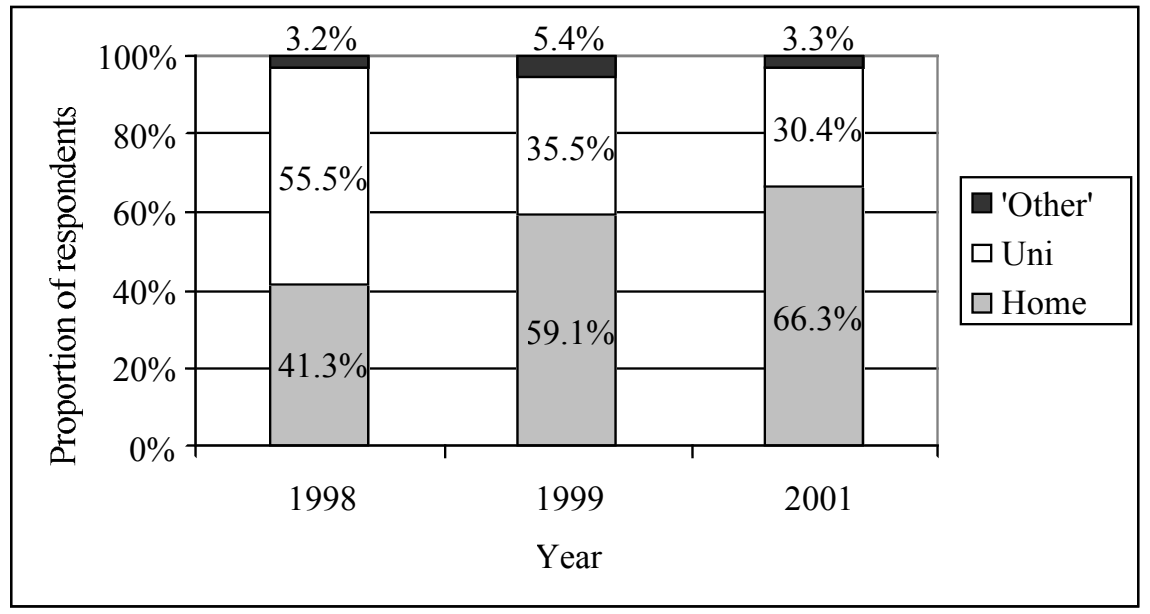

Figure 1: Reported source of Internet / WWW access

From Table 4 and 6 it is noted that, while all respondents (by 2001) indicated that they had access to a computer, a small proportion of commencing students ( 7.9 percent) believed they did not have access to 
the Internet / WWW when, in fact, all students, both on and off campus, are provided a computer account through Deakin University that permits access to the Internet, and all on campus students have access to a large number of both PC and Mac workstations in on campus computer laboratories. Closer inspection of the data reveals that all off campus respondents indicated they had access to the Internet / WWW, even though this means that they must organise their own access through their workplace or a private Internet Service Provider (ISP). So a significant minority of commencing on campus students are unaware of the computing facilities provided for them by the university. This result is broadly in agreement with 3.7 percent of Deakin University first year chemistry students reporting themselves as unaware of the on campus computer laboratories (Lim \& Lee, 2000). This perhaps represents the fact that at the commencement of their studies, some on campus students are still orienting themselves to university life, and do not yet fully appreciate what resources are on offer to them. An induction program in computing for on campus students could be beneficial, a conclusion also reached by Lim \& Lee (2000).

The growing proportion of students with Internet / WWW (and presumably computer) access at home is important. While Deakin University provides on campus students with free access to computer workstations and the Internet, this access is only available while the student is on campus and has free time between classes and other study activities. The literature suggests that some students do not necessarily view the physical presence of on campus computer labs as equating to 'having access to computers'. Althaus (1997) notes that students who do not have their own computing equipment must make special trips to computer labs and vie with other students for access to computers. Interestingly, the same source quotes an engineering student explaining their lack of participation in a class computer exercise as follows:

I didn't dislike it, it was just inconvenient for me. I am an engineering major, and spend 30-40 hours / week doing problem sets. I do not have a computer w/modem in my room, and I only go to the computer lab to solve problems or write programs. (Althaus, 1997, 170)

There are important considerations in the use of the Internet / WWW by students that go beyond mere access to computing facilities and the Internet. Even when everyone is 'online', not everyone may have the same type of connection. On campus students may have the benefit of high speed, dedicated networking, whereas the only option for an off campus student may be a dialup modem line that does not support the data transfer rate required for high quality interactive multimedia programs (Ingram, 1996). Additionally, simply having the requisite computer resources doesn't automatically grant access to the information 
superhighway. If one is unfamiliar with computers or the Internet, attempting to navigate this new medium can be frustrating and frightening. A survey of 158 postgraduate students, composed of roughly equal numbers of on and off campus students, reported that even though more than 90 percent of students had access to a computer, 75 percent of all students stated a need for training in the use of the Internet (Brogan, 1997).

\section{Email use}

Table 7 gives the proportions of respondents in the SEB121 groups who indicated that they were 'regular' users of email. While the self assessment by respondents as to what constitutes regular email usage may be somewhat subjective, the results showed a marked increase in regular usage over time. Based on the large sample inference about two proportions test, the level of reported regular email usage between 1998 and 1999 was not significantly different $(Z=0.27, p>0.78)$ however, when all three groups of results were considered, based on the Chi-square test of homogeneity, the distributions of reported regular email usage were significantly different $\left(\chi_{2}^{2}=30.37, \mathrm{p}<2.6 \times 10^{-7}\right)$.

Table 7: Reported regular usage of email

\begin{tabular}{|c|c|c|}
\hline Year & Regular email user & Not a regular email user \\
\hline 1998 & $40.8 \%$ & $59.2 \%$ \\
\hline 1999 & $38.8 \%$ & $61.2 \%$ \\
\hline 2001 & $73.3 \%$ & $26.7 \%$ \\
\hline
\end{tabular}

\section{Correlations}

Two consistently strong correlations were observed in all three sets of data for the SEB121 groups; the older a respondent was the more likely they were to report studying in off campus mode, and, a respondent reporting themselves as being a regular user of email was also likely to report themselves as being a regular user of the Internet / WWW. For all three years the distributions of age had significantly different variance between the two study modes, and the distributions were generally not normal, so the large sample inference about two means based on the standard Gaussian distribution was the appropriate method to test the significance of the difference in mean respondent age versus study mode. The large random sample permits the use of a large sample inference using the Chisquare test of independence between respondents reporting themselves as regular users of email and regular users of the Internet / WWW. Table 8 gives the significance of these correlations. 
Table 8: Significance of observed correlations in respondent data

\begin{tabular}{|l|l|l|l|}
\hline Observed correlation & SEB121 1998 & SEB121 1999 & SEB121 2001 \\
\hline Age and study mode & $\begin{array}{l}\mathrm{Z}=-6.31 \\
\mathrm{p}<2.8 \times 10^{-10}\end{array}$ & $\begin{array}{l}\mathrm{Z}=-9.74 \\
\mathrm{p}=0.0\end{array}$ & $\begin{array}{l}\mathrm{Z}=-6.17 \\
\mathrm{p}<7.1 \times 10^{-10}\end{array}$ \\
\hline $\begin{array}{l}\text { Regular use of email } \\
\text { and Internet / WWW }\end{array}$ & $\begin{array}{l}\chi_{1}^{2}=47.54 \\
\mathrm{p}<5.4 \times 10^{-12}\end{array}$ & $\begin{array}{l}\chi_{1}^{2}=59.29 \\
\mathrm{p}<1.4 \times 10^{-14}\end{array}$ & $\begin{array}{l}\chi_{1}^{2}=37.50 \\
\mathrm{p}<9.2 \times 10^{-10}\end{array}$ \\
\hline
\end{tabular}

These observed correlations were as expected. As noted above, for commencing students, virtually all conventional entry (18 year old) students will study on campus, and many mature age students will study off campus to best suit their work, family or other commitments. Respondents reporting familiarity with or regular use of one online tool (email or Internet / WWW) could reasonably be expected to also be regular users of the other. It is an anecdotal observation of the authors that a majority of the on campus members of the student group in question now use a WWW based interface to access their email, permitting them to access their email from any location at which they can operate a WWW browser, rather than using a dedicated email client program that can only be operated where the client program is installed.

\section{Changes in usage patterns over the duration of studies}

While the data collected from the SEB421 group in 1998 is not directly comparable to the SEB121 group data from the same year, it does provide an indication in the difference in responses between first year first semester commencing students and final year final semester completing students. Table 9 gives the comparison of 1998 data for the two student groups. By the final semester of their studies all respondents indicated having access to a computer and the Internet / WWW, and most were regular users of the Internet / WWW. The mean computer usage per week was higher, and more than three quarters indicated themselves as regular users of email.

Table 9: Comparison of 1998 data for SEB121 and SEB421 respondent groups

\begin{tabular}{|l|c|c|}
\hline Questionnaire category & SEB121 response & SEB421 response \\
\hline Have access to a computer & $96.0 \%$ & $100 \%$ \\
\hline $\begin{array}{l}\text { Mean hours per week } \\
\text { computer usage }\end{array}$ & $\begin{array}{c}10.6(13.36) \\
\text { hours }\end{array}$ & $\begin{array}{c}12.0(10.28) \\
\text { hours }\end{array}$ \\
\hline Internet / WWW access & $84.2 \%$ & $100 \%$ \\
\hline Regular Internet / WWW user & $46.1 \%$ & $92.3 \%$ \\
\hline Regular email user & $40.8 \%$ & $76.9 \%$ \\
\hline
\end{tabular}




\section{Conclusions}

A longitudinal analysis of computer usage by commencing students enrolled in Deakin University's undergraduate engineering and technology programs over the period 1998 to 2001 revealed that:

- while access to computers had not increased significantly, it was at high levels in all years and was most recently reported at 100 percent;

- mean computer usage (in average hours per week) for off campus students had not changed significantly, last reported at 24.8 hours per week; but, had risen significantly for on campus students, from 6.0 to 11.7 hours per week;

- while access to the Internet / WWW had not increased significantly, last reported at 92.1 percent, reported regular use of the Internet / WWW had risen significantly, from 46.1 to 82.0 percent;

- while most students continued to report their source of Internet / WWW access as either Home or University, currently at 96.7 percent combined, the proportion of students reporting Home as their source of Internet / WWW access had risen significantly from 41.3 to 66.3 percent;

- while the reported regular use of email did not vary significantly between 1998 and 1999, it did rise significantly between 1998 and 2001, from 40.8 to 73.3 percent; and

- strong correlations were observed in all sets of data between student age and study mode, and between reported regular use of email and reported regular use of the Internet / WWW - these correlations were expected.

A comparison of questionnaire responses received from commencing and completing students in the same year (1998) suggests that over the four year duration of their studies the student's usage of computers, the Internet / WWW and email will all increase, presumably because of the requirement for students to use computers in many areas of their studies in all years of their course. The high reported levels of computer and Internet / WWW access and usage suggest that earlier concerns about making access to computers a mandatory requirement for student enrolment in engineering and technology programs at Deakin University are now unfounded.

However, while it might now be reasonable to assume that all students have access to computers and the Internet / WWW, it should be kept in mind during the development of computer based and/or online teaching 
learning resources that there are various classes of access. Students accessing materials in an on campus computer laboratory with wide band Internet access will have a different experience to off campus students paying time and/or volume charges to an ISP for modem based dialup access to the Internet.

Additionally, in this study and a similar one of commencing chemistry students at Deakin University, a small but not insignificant proportion of commencing students were unaware of the computing facilities provided for on campus students by the university. Given the importance of computing in engineering and technology studies, an orientation program covering computing facilities and services provided by the university would be of benefit to all commencing students.

\section{References}

Althaus, S. L. (1997). Computer-mediated communication in the university classroom: An experiment with on-line discussions. Communication Education, 46(3), 158-174.

Ash, G. (1996). Occasional Papers in Open and Distance Learning - Computer information technology survey for the School of Agriculture (No. 19). Wagga Wagga: Open Learning Institute, Charles Sturt University.

Briggs, H. (1995). Towards student-centred engineering education at Deakin University. Paper presented at the 12th Biennial Forum of the Open and Distance Learning Association of Australia, Vanuatu.

Brogan, M. (1997). Off-campus and off-line? Access to the Internet of postgraduate TESOL students at Deakin University. In T. Evans \& V. Jakupec \& D.

Thompson (Eds.), Research in Distance Education, 4, 115-127. Geelong: Deakin University Press.

Department of Education Training and Youth Affairs. (1999). Selected Higher Education Statistics (Higher Education Statistics Collection 6262.HEDS98A). Canberra, Australia: Department of Education, Training and Youth Affairs.

Ferguson, C., \& Florance, J. (1999). Internet Access to a Flexible Manufacturing Cell. Paper presented at the Second World Manufacturing Congress International Symposium on Manufacturing Systems, University of Durham, UK.

Flowers, L., Pascarella, E. T., \& Pierson, C. T. (2000). Information technology use and cognitive outcomes in the first year of college. Journal of Higher Education, 71(6), 637-667.

Ingram, A. L. (1996). Teaching with technology. Association Management, 46(6), 3847. 
Lim, K. F., \& Lee, J. (2000). IT skills of university undergraduate students enrolled in a first year unit. Australian Journal of Educational Technology, 16(3), 215-238. http:/ / www.ascilite.org.au/ajet/ajet16/lim.html

Palmer, S., \& Tulloch, W. (2001). The evolution of on-line teaching and learning in engineering at Deakin University. Journal of Computing in Higher Education, 13(1), 91-109.

Ryan, Y. (1998). Time and tide: Teaching and learning online. Australian Universities' Review, 41(1), 14-19.

Ubell, R. (2000). Engineers turn to e-learning. IEEE Spectrum, 37(10), 59-63.

\section{Appendix}

\section{Computer Use Survey - Start of Semester}

This brief survey is aimed at determining the general level of exposure to, and use of computers, by the class, as a whole. It will be used to help improve the computer resources and training provided to engineering and technology students.

Please note that participation is voluntary, all data will remain anonymous and confidential. The results may be published, but only in an aggregate form, results will not be related to any individual student.

By completing this form you consent to participate in this survey.

\section{General}

Please state your age at your last birthday

[ ] Yrs

Please indicate your gender (circle $\mathrm{M}$ or $\mathrm{F}$ )

M F

Please indicate your study mode (circle On or Of campus) ..

On Off

\section{Computer Usage}

Have you used a computer before? (circle $\mathrm{Y}$ or $\mathrm{N}$ )

Do you use a computer regularly? (circle $\mathrm{Y}$ or $\mathrm{N}$ )

If no, please go to question 3

If yes, what type? (circle one) - PC / Mac / Other

If 'Other', please specify type

How many hours per week (on average) do you spend using a computer? 


\section{Computer Access}

Do you have access to a computer? (circle $\mathrm{Y}$ or N)

If no, please go to question 4

If yes, who does the computer belong to? (circle one)

You / Your family / Your employer / A friend / Other

If 'Other', please specify who it belongs to

\section{Internet Usage}

Do you regularly use e-mail? (circle $\mathrm{Y}$ or $\mathrm{N}$ )

If yes, do you use your own e-mail account, or do you use someone else's? (circle one) - Own Acct / Someone else's

Do you regularly use the World Wide Web? (circle Y or N) .

Have you ever created a Web page? (circle $\mathrm{Y}$ or $\mathrm{N}$ )

Do you have access to the Internet/WWW? (circle $\mathrm{Y}$ or N) ..

If yes, where do you have access? (circle one)

Home / Work / School / University / Other

If 'Other', please specify where you have access

\section{Other}

What do you think computers most useful for?

What task do you use computers for most?

What computer program do you use the most?

\section{Thank you for your time and cooperation}

Stuart Palmer, Senior Lecturer, School of Engineering and Technology Deakin University, Geelong, Victoria, 3217, Australia

Email: spalm@deakin.edu.au Web: http: / / www.deakin.edu.au/ spalm

Sharyn L. Bray, School of Engineering and Technology, Deakin University 